\title{
Correction to: Characterization of biocontrol microorganisms from the rhizoplane of Decalepis arayalpathra and screening of secondary metabolites
}

\author{
Shikha Srivastava ${ }^{1,2,3} \cdot$ Ved Pal Sing $\mathrm{h}^{1,2,3}$
}

Published online: 14 May 2020

(c) Society for Plant Research 2020

\author{
Correction to: Vegetos \\ https://doi.org/10.1007/s42535-020-00115-8
}

Publisher's Note Springer Nature remains neutral with regard to jurisdictional claims in published maps and institutional affiliations.

The original version of this article unfortunately contained a mistake. In section "Acknowledgements", the last sentence was incomplete. The correct wording of "Acknowledgements" is:

Acknowledgements: The authors are grateful to Prof. K. S. Rao (HOD), Department of Botany, University of Delhi, for providing necessary facilities to carry out this work. The authors are thankful to the Director, CSIR-CIMAP, Lucknow, for providing the in-vitro samples to carry out this work. Financial supports from Non-Net fellowship (no. Sch/Non-NET/139/2014-15/51) from DU/UGC are gratefully acknowledged. The author is highly thankful to Dr. Balaram Pani, Principal, Bhaskaracharya College of Applied Sciences (University of Delhi), for his encouragement and support to publish this work.

The original article can be found online at https://doi.org/10.1007/ s42535-020-00115-8.

Shikha Srivastava

shikhaminty@gmail.com

1 Department of Botany, Faculty of Science, University Enclave, University Road, New Delhi 110007, India

2 Present Address: Department of Botany, Bhaskaracharya College of Applied Science, Phase 1, Dwarka, New Delhi 110075, India

3 Present Address: Department of Biochemistry, Innovative College of Pharmacy, Knowledge Park-II, Greater Noida, Uttar Pradesh 201306, India 